\title{
COMPARISON OF DIBENZODIOXIN LEVELS IN BLOOD AND MILK IN AGRICULTURAL WORKERS AND OTHERS FOLLOWING PENTACHLOROPHENOL EXPOSURE IN CHINA
}

\author{
Schecter, A. ${ }^{A}$, Jiang, K., ${ }^{B}$ Päpke, O., ${ }^{C}$ Fürst, P., ${ }^{D}$ and Fürst, $C .^{D}$ \\ ADepartment of Preventive Medicine, Clinical Campus, State University of New York, Health Science \\ Center-Syracuse, 88 Aldrich Ave, Binghamton, NY 13903, USA. \\ ${ }^{B}$ Research Center for Eco Environmental Sciences, Academia Sinica, PO Box 2871, Beijing, 100085, China. \\ ${ }^{\mathrm{C}}$ ERGO Forschungsgesellschaft mbH, Albert-Einstein Ring 7, 22761 Hamburg, Germany. \\ ${ }^{D}$ Chemisches Landes- und Staatliches Veterinäruntersuchungsamt, Sperlichstrasse 19, 48151 Münster, \\ Germany.
}

Keywords: Dibenzodioxins, dibenzofurans, pentachlorophenol, Na-PCP, blood, milk, China, agricultural workers.

Abstract: Substantial amounts of sodium pentachlorophenol (Na-PCP) salts have been sprayed in certain areas in central China since the 1960 s for control of snail-borne schistosomiasis. A sample of Na-PCP used in the area of concern was analyzed and showed 2,3,7,8-substituted dibenzodioxin (PCDD) and dibenzofuran (PCDF) congeners as well as some non-2,3,7,8-substituted congeners. Dibenzodioxin analysis of two pooled blood samples from 100 persons living in sprayed areas and a pooled sample from 26 individuals who had direct contact with the Na-PCP showed elevations of PCDD/F congeners found in the Na-PCP. Total $\mathrm{PCDD} /$ Fs ranged from 631 to 1252 parts per trillion (ppt) lipid in the blood of those exposed to Na-PCP, while two general population age-matched pooled blood samples from 50 persons each had total PCDD/Fs of 147 and $178 \mathrm{ppt}$. Toxic equivalents calculated with International Toxic Equivalency Factors (I-TEqs) ranged from 9 to $16.3 \mathrm{ppt}$ in the blood samples from exposed persons while the general population blood ITEqs were 4.8 and $6.4 \mathrm{ppt}$. A pooled breast milk sample from 50 women living in the sprayed areas was compared with a pooled sample from 50 women living in unsprayed areas. Total PCDD/Fs was low in both exposed and general population samples (134 and $42 \mathrm{ppt}$ lipid, respectively), however, the women living in sprayed areas had considerably higher PCDDs, $129 \mathrm{ppt}$ versus $34 \mathrm{ppt}$. The mothers exposed to Na-PCP had a I-TEq of 5.4, which was about double that of the mothers from the general population, $2.6 \mathrm{ppt}$, lipid. Although human PCDD and PCDF tissue levels in China are low compared with those in more industrialized countries, the higher levels in exposed persons are cause for concern.

Introduction: Chinese investigators (headed by K.J.) concerned about PCP and dibenzodioxin environmental contamination initiated this pilot collaborative study to assess possible elevated dibenzodioxin body burden following human exposure to sodium pentachlorophenol (Na-PCP). The Na-PCP had been sprayed since the 1960 s to control snails that spread schistosomiasis. ${ }^{(1)}$ Individuals living in sprayed areas were 
potentially exposed to dibenzodioxins and dibenzofurans and were at risk of intake and increased dibenzodioxin body burden. Pooled human blood and breast milk samples from a middle China province where Na-PCP has been used for over thirty years were collected as well as general population comparably age-matched samples from unsprayed areas 300 kilometers distant. One sample of the Na-PCP salt used, which was manufactured in Tianjin, China, was also analyzed for PCDDs and PCDFs.

Methods: The groups studied were (a) sprayers or handlers of Na-PCP, (b) persons living in the sprayed areas, and (c) persons living in unsprayed areas a distance of 300 kilometers away. Pooled whole blood or milk samples and the Na-PCP were collected by one of us (J.K.) and transported (by A.S.) to the U.S. and shipped to the laboratories. All human samples were frozen immediately after collection and kept frozen until dibenzodioxin analysis was performed. The human breast milk was analyzed in Münster, Germany (P.F. \& C.F.) and the blood in Hamburg, Germany (O.P.) using previously described methods. ${ }^{(24)}$ The analytic methods were used by the dibenzodioxin laboratories in successful participation and "certification" in recent WHO interlaboratory validation studies on human tissues. ${ }^{(5)}$

Results: Table I presents congener-specific dibenzodioxin analysis results and calculated I-TEq $q^{(68)}$ for a sample of Na-PCP and two pooled human breast milk samples from women for the most part in their twenties (each $\mathrm{n}=50$ ). The Na-PCP had detectable levels in parts per billion (ppb) of most of the $2,3,7,8$ substituted congeners as well as some non-2,3,7,8-substituted congeners (see footnotes on Tables I \& II) with the dibenzodioxins predominating in amount over the dibenzofurans, 854 versus $97 \mathrm{ppb}$, respectively. Although Na-PCP does not usually contain $2,3,7,8-\mathrm{TCDD},{ }^{(9)}$ this sample had $1.1 \mathrm{ppb}$ out of $951 \mathrm{ppb}$ total PCDD/Fs. The calculated total I-TEq was $30 \mathrm{ppb}$. Most of the dibenzodioxin toxicity is from 1,2,3,4,7,8HxCDD, with $238 \mathrm{ppb}$ contributing 23.8 to the total I-TEq of $30 \mathrm{ppb}$. Elevations of $1,2,3,4,7,8-\mathrm{HxCDD}$ are also seen in the human milk samples from sprayed areas when compared with those from unsprayed areas, 11.1 and $0.74 \mathrm{ppt}$, respectively. The general population breast milk had total PCDD/Fs of 42 and an I-TEq of $2.6 \mathrm{Ppt}$, lipid, whereas pooled breast milk from residents of areas sprayed with Na-PCP had total PCDD/Fs of 134 and an I-TEq of $5.4 \mathrm{ppt}$, lipid. Certain congeners were elevated to varying degrees in milk from the exposed group including 2,3,7,8-TCDD (1.4 vs. $0.64 \mathrm{ppt}$ ), 1,2,3,7,8-PeCDD (3.4 vs. $0.7 \mathrm{ppt}$ ), 1,2,3,4,7,8-HxCDD (11.1 vs. 0.74 ppt), 1,2,3,4,6,7,8-HpCDD (7.1 vs. $3.3 \mathrm{ppt}$ ) and OCDD (103 vs. 26.8ppt). This pattern appears to be consistent with the pattern of dibenzodioxin congeners found in the Na-PCP sample.

Table II lists the dibenzodioxin, dibenzofuran, and I-TEq of five pooled blood samples. Two general population samples (each $n-50$ ) were obtained for comparison, one from persons fifteen to nineteen years of age and one from men and women over forty who lived $300 \mathrm{~km}$ from the sprayed areas. Total dibenzodioxin levels varied from 126 to $150 \mathrm{ppt}$, dibenzofurans from 22 to 28 , total PCDD/Fs were 147 and 178, and I-TEq were 5 and $6 \mathrm{ppt}$ lipid, in younger versus older general population samples, respectively. As expected, levels in the older population were slightly higher than in the younger group, due to the typical 


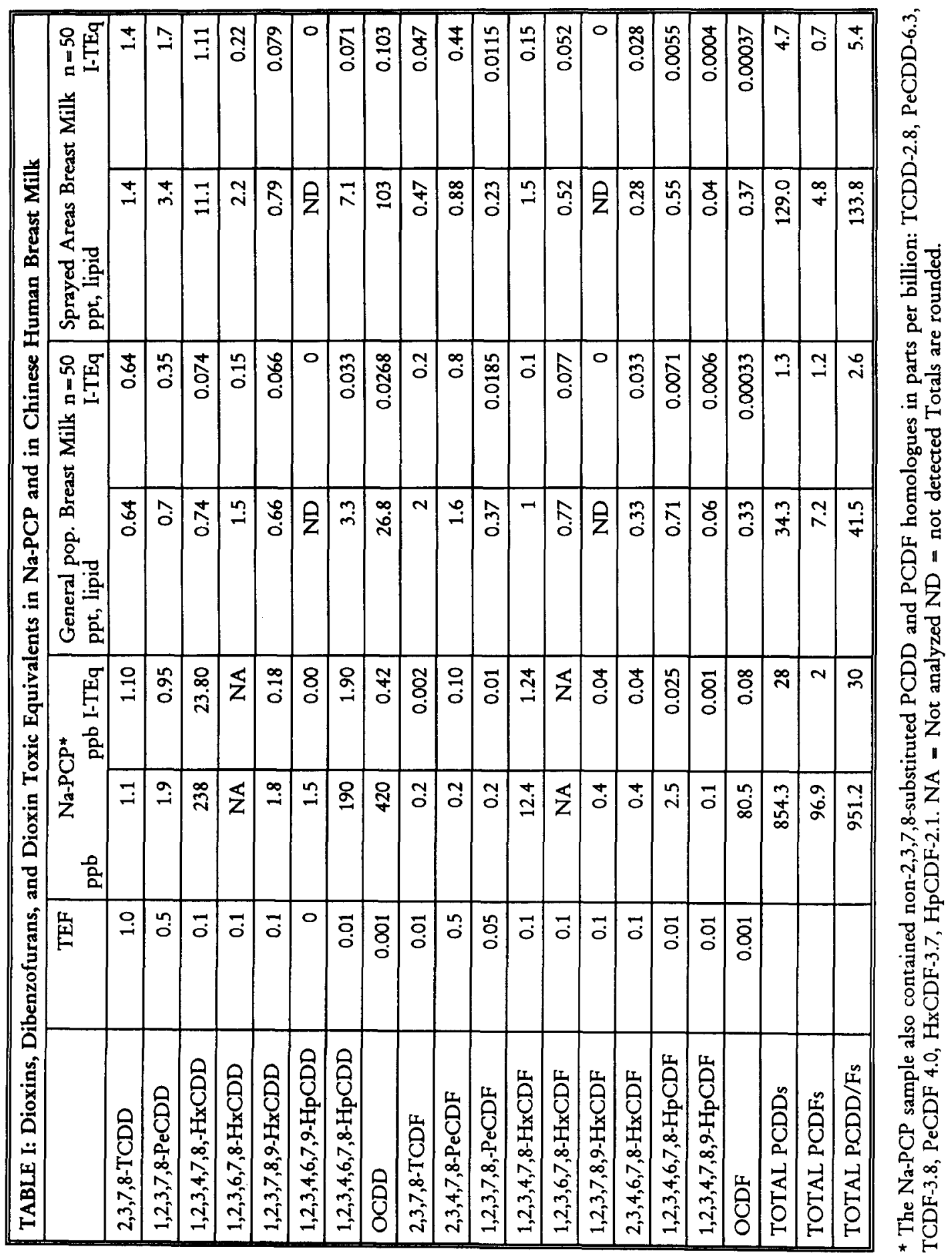




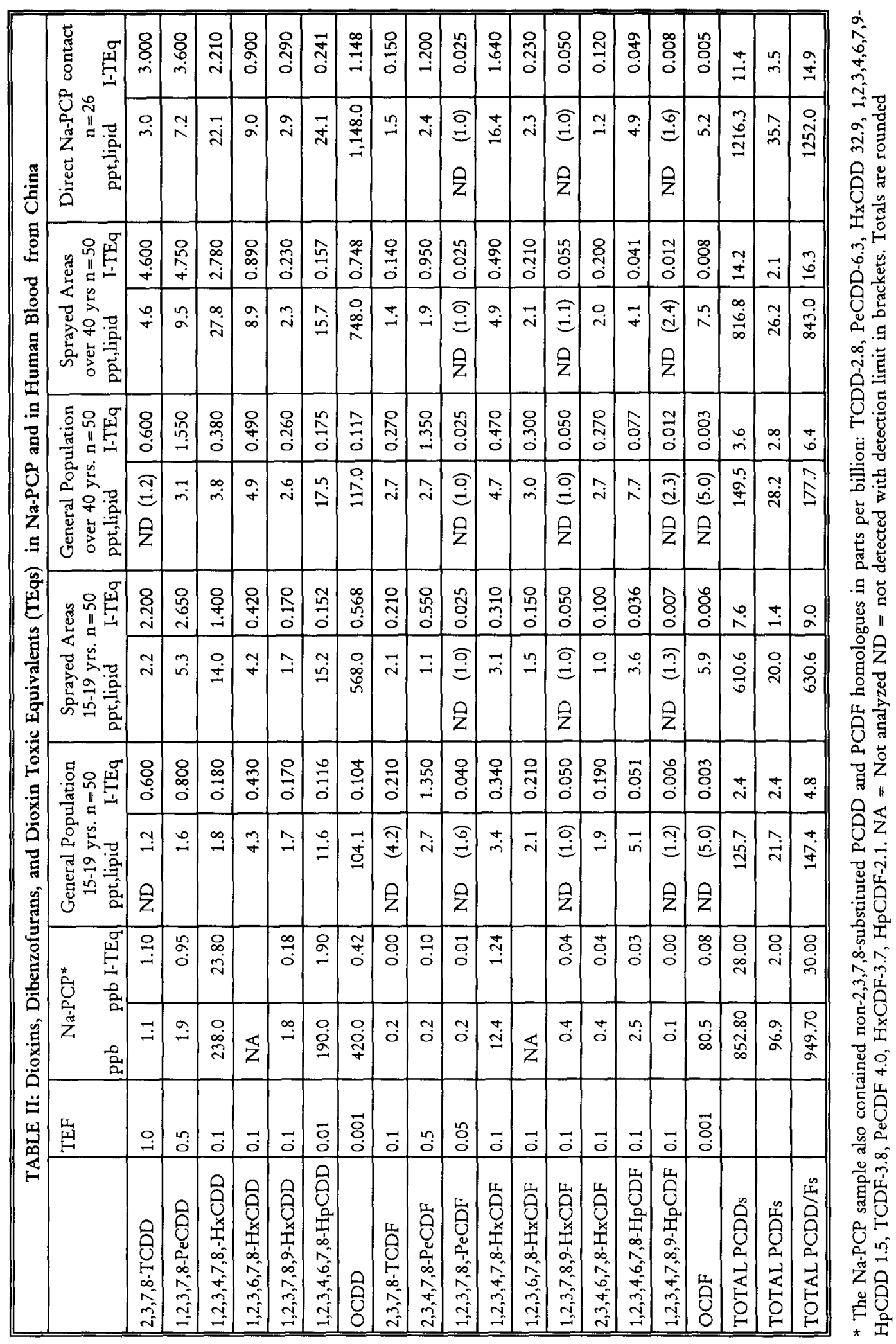


accumulation of dibenzodioxins over time.

Three pooled blood samples were collected from residents of a rural area who lived and worked in the sprayed areas and were potentially exposed to the Na-PCP: one from persons fifteen to nineteen years old $(n=50)$, one from men and women over forty $(n=50)$, and one from persons in charge of distributing the Na-PCP, some of whom handled or sprayed the molluscacide $(n=26)$. Total PCDD/F levels were 631, 843, and 1252, and total I-TEq equivalents were 9, 16, and 15, respectively, in the samples from persons potentially exposed to Na-PCP. In the exposed younger group, 2,3,7,8-TCDD, 1,2,3,7,8-PeCDD, 1,2,3,4,7,8$\mathrm{HxCDD}$ and $\mathrm{OCDD}$ were elevated compared with the reference group. The older group living in sprayed areas had elevations of 2,3,7,8-TCDD, 1,2,3,7,8-PeCDD, 1,2,3,4,7,8-HxCDD, 1,2,3,6,7,8-HxCDD, and OCDD compared with controls. Adults having direct contact with the Na-PCP had elevations of 2,3,7,8-TCDD, 1,2,3,7,8-PeCDD, 1,2,3,4,7,8-HxCDD, 1,2,3,6,7,8-HxCDD, OCDD, and 1,2,3,4,7,8-HxCDF when compared with the general population over forty years of age which is consistent with intake of the congeners present in the Na-PCP. As we previously noted, general population and individual PCDD and PCDF levels in human blood are generally higher than in human milk. This is especially the case for OCDD, which is found at much higher levels in blood than milk.

In order to better visualize and compare the congener levels in the various groups, the data is presented in graphical format in a series of figures. Figure 1 presents the 2,3,7,8-substituted PCDD/F levels measured in the Na-PCP sample in parts per billion. Figure 2 is a graphical comparison of PCDD/F levels (ppt, lipid) in the pooled milk sample from unsprayed areas with those in the sample from women living in sprayed areas which shows higher levels of dibenzodioxins but not of most dibenzofurans. Of the dibenzofurans, only $1,2,4,7,8 \cdot \mathrm{HxCDF}$ is elevated in the human milk sample from exposed women, as it and $\mathrm{OCDF}$ are in the pooled blood of those with direct Na-PCP contact. This is consistent with the finding that $1,2,3,7,8-\mathrm{HxCDF}$ and OCDF are the PCDF congeners present in the highest amounts in the Na-PCP. Figure 3 shows, in a paired fashion, the PCDD/F levels (ppt, lipid) of the pooled blood results for all groups. Figure 4 presents the PCDD/F I-TEq levels (ppt, lipid) of the pooled blood for the various groups. The large contribution of the PCDDs relative to PCDFs can be noted in both PCDD/F levels and I-TEqs for the exposed groups.

Conclusion \& Discussion: Human tissue dibenzodioxin levels appear to be low in China as they are in other less industrialized countries. ${ }^{(10)}$ The samples reported here have somewhat lower levels than the mean of our previously published seven individual Chinese human adipose general population tissue specimens from Shanghai where total PCDDs were 247 and PCDFs were $53 \mathrm{ppt}$, lipid. ${ }^{(1)}$ This might be due to the difference in dibenzodioxin levels in blood as compared to adipose tissue even when reported on a lipid basis or might be caused by the difference in diet from different regions in China. Shanghai is a large, modern city with a high degree of industrialization while the sprayed area where these samples were obtained is in a relatively underdeveloped, rural province where dietary habits may be substantially different; there may be less consumption of dibenzodioxin-contaminated meat, fish and milk and with higher consumption of rice 
Figure 1: PCDD/Fs in a Sample of Na-PCP from China

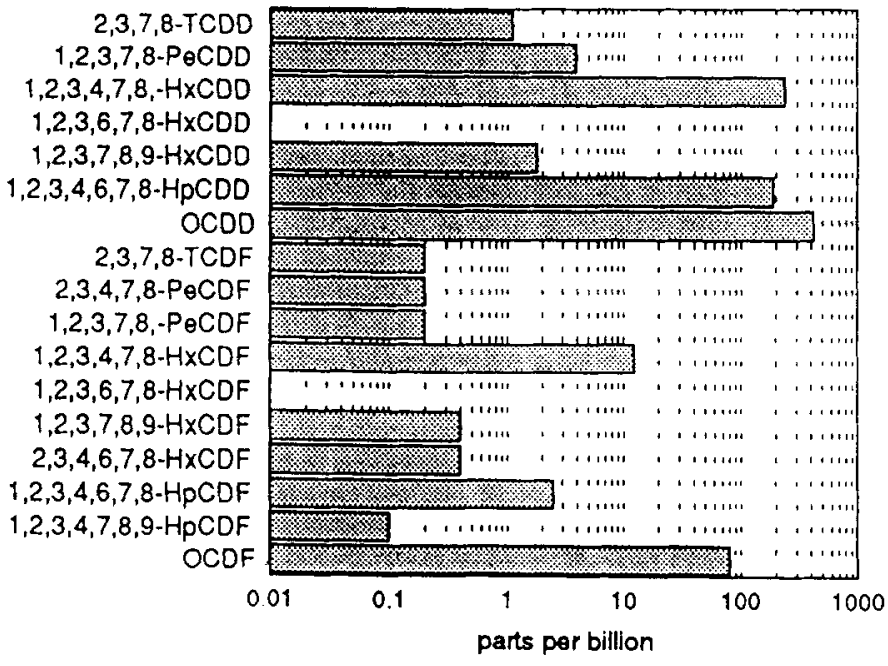

Figure 2: PCDD/Fs in Human Breast Milk from China

$2,3,7,8-T_{C D O}$

$1,2,3,7,8-P_{\theta} C D D$

$1,2,3,4,7,8,-H \times C D D$

$1,2,3,6,7,8-\mathrm{H} \times \mathrm{CDD}$

$1,2,3,7,8,9-\mathrm{H} \times C D D$

$1,2,3,4,6,7,8-\mathrm{HPCDD}$

OCDD

$2,3,7,8-T C D F$

$2,3,4,7,8 \cdot \mathrm{PeCDF}$

$1,2,3,7,8,-P \oplus C D F$

$1,2,3,4,7,8-\mathrm{HxCDF}$

$1,2,3,6,7,8-\mathrm{H} \times \mathrm{CDF}$

$1,2,3,7,8,9-\mathrm{H} \times \mathrm{CDF}$

$2,3,4,6,7,8-\mathrm{H} \times \mathrm{CDF}$

$1,2,3,4,6,7,8-\mathrm{H \rho CDF}$

$1,2,3,4,7,8,9-\mathrm{HPCDF}$ OCDF

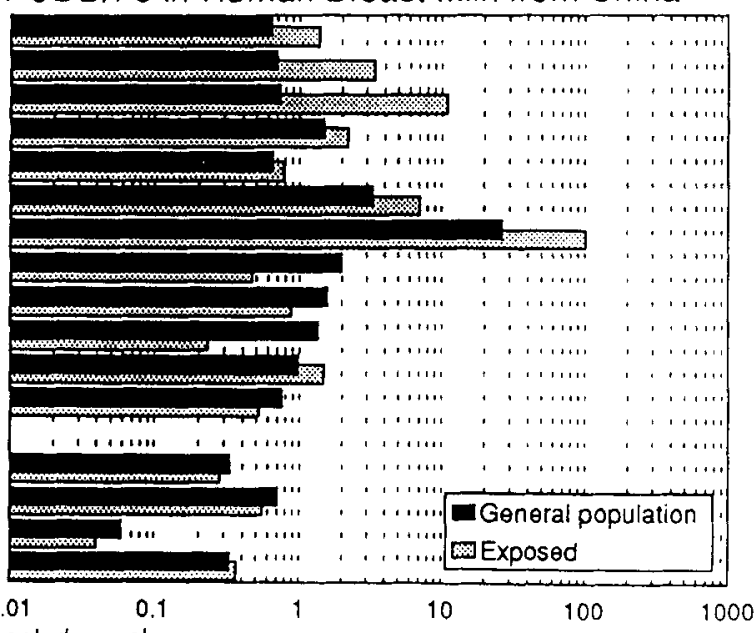

$n=50$ for each pooled sample, parts pertrilion 
Figure 3: PCDD/Fs in Human Blood from China

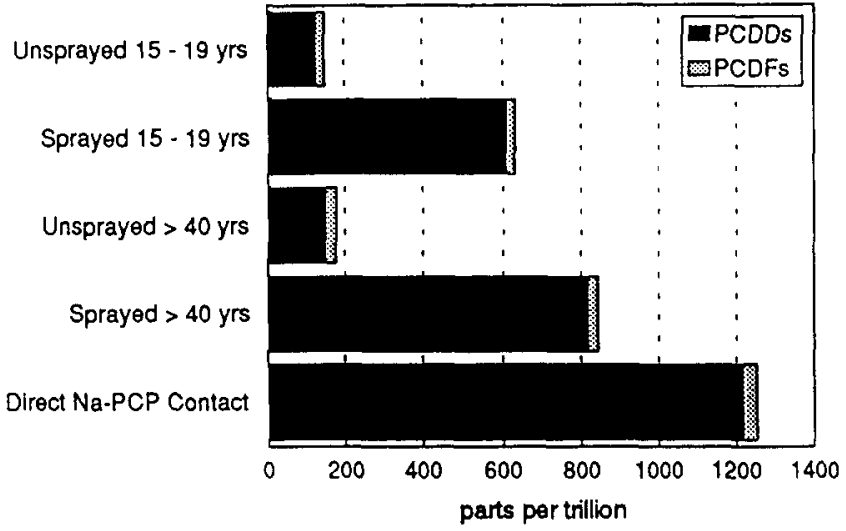

$n=50$ for all except direct Na-PCP contact $n=26$

Figure 4: PCDD/F TEqs in Human Blood from China

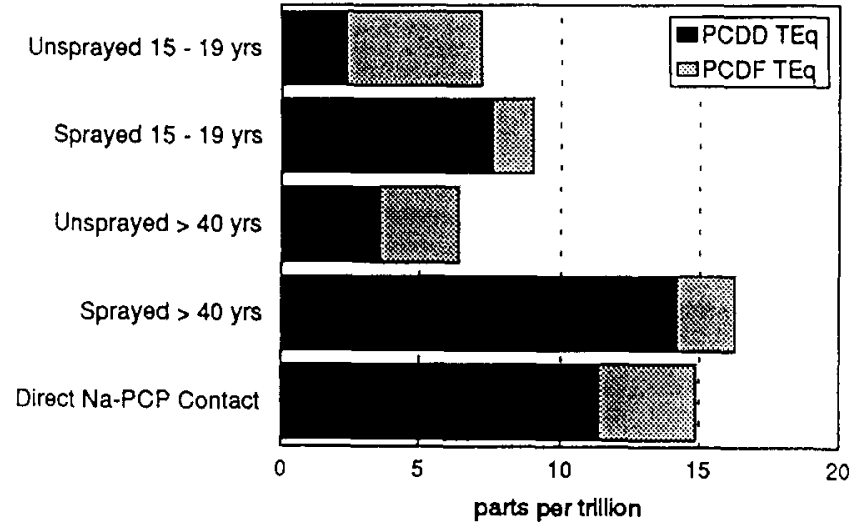

$n=50$ for all except direct Na-PCP contact $n=26$ 
and other vegetables.

Within the same province, the persons exposed to Na-PCP have two to three times the amount of dibenzodioxins and I-TEq as compared to the general population, while for the most part, their dibenzofuran levels are similar. This is consistent with uptake from Na-PCP where our sample had higher levels of dibenzodioxins than dibenzofurans and dibenzodioxins contributed ten times more toxicity than dibenzofurans. Intake may occur through skin contact, by inhalation, and through ingestion from the food chain.

Reflecting up to thirty years of Na-PCP exposure, the blood sample from persons over forty has higher total dibenzodioxins and I-TEqs than the sample from younger persons and the sample from those who had direct contact with the Na-PCP. The persistence of dibenzodioxins in human tissues has been established in other cases where initial exposure occurred twenty to thirty years ago. ${ }^{(12-14)}$ We interpret the findings as being consistent with lower levels of environmental chemical use and contamination in China as compared with more industrial countries. For instance, in Germany the mean total I-TEq in blood was determined to be $26 \mathrm{ppt},{ }^{(15)}$ and the mean total I-TEq for the human milk was determined to be $29.3 \mathrm{ppt} .{ }^{(16)}$ The German I-TEq values are much higher than the levels from sprayed and non-sprayed areas in China (Table I and Table II). The typical Chinese diet consists of little meat, fish, and milk, which are known to be major contributors to dioxins in the general populaion. ${ }^{(17-19)}$ It is of interest that persons with direct $\mathrm{Na}$ PCP contact had higher PCDD/Fs of 1252 ppt compared to adults living in sprayed areas with PCDD/Fs of 843 while the adults living in sprayed areas had a higher I-TEq, $16.3 \mathrm{ppt}$, than those with direct contact at 14.9 ppt.

Chinese workers and scientists are concerned about dibenzodioxin contamination and steps have been taken to replace Na-PCP as a molluscacide. (1) Further study of the food chain and individual blood analyses would help to better characterizing environmental contamination from Na-PCP.

Acknowledgements: This work was supported in part by the C.S. Fund and the National Natural Science Foundation of China. Thanks are extended to Ruth Stento for technical assistance in manuscript preparation.

\section{References:}

1. Jiang, K., Chen, Y-D., Li, L-J. and Schecter, A. Dioxins in Chinese pentachlorophenol. Organobalogen Compounds, Eco-Informa Press, Bayreuth, Germany 11:319-320, 1993.

2. Fürst, P., Meemken, H.A., Krüger, Chr. and Groebel, W. Polychlorinated dibenzofurans and dibenzodioxins in human milk from Western Germany. Chemosphere 16:1983-1988, 1989.

3. Päpke, O., Ball, M., Lis, Z.A. and Scheunert, K. PCDD/PCDF in whole blood samples of unexposed persons. Chemosphere 19:941-948, 1989. 
4. Päpke, O., Ball, M., Lis, Z.A. and Scheunert, K. Determination of PCDD/PCDF in whole blood from persons involved in fire incidents. Chemosphere 20:7/9:959-966, 1990.

5. World Health Organization, Levels of PCBs, PCDDs and PCDFs in buman milk and blood: Second round of quality control studies - Environment and Health in Europe \#37, Denmark:FADL Publishers, 1991. pp. 1-76.

6. Pilot Study on International Information Exchange on Dioxins and Related Compounds, International Toxicity Equivalency Factor (I-TEF) Method of Risk Assessment for Complex Mixtures of Dioxins and Related Compounds. Report Number 176, Committee on the Challenges of Modern Society:North Atlantic Treaty Organization, 1988. pp. 1-26.

7. Pilot Study on International Information Exchange on Dioxins and Related Compounds, Scientific Basis for the Development of the International Toxicity Equivalency Factor (I-TEF) Method of Risk Assessment for Complex Mixtures of Dioxins and Related Compounds. Report 178, Committee on the Challenges of Modern Society:North Atlantic Treaty Organization, 1988. pp. 1-56.

8. USEPA, Interim procedures for estimating risks associated with exposures to mixtures of chlorinated dibenzo-p-dioxins and dibenzofurans (CDDs and CDFs) and 1989 update, Springfield, VA 22161 PB90-145756:U.S. Department of Commerce, National Technical Information Service, 1989.

9. Hagenmaier, H. Determination of 2,3,7,8-tetrachlorodibenzo-p-dioxin in commercial chlorophenols and related products. Fresenius Z.Anal.Chem. 325:603-606, 1986.

10. Schecter, A.J. Dioxins and Related Chemicals in Humans and the Environment. In: Banbury Report 35: Biological basis for risk assessment of dioxins and related compounds, edited by Gallo, M., Scheuplein, R.J. and Vander Heijden, K.A. Cold Spring Harbor, NY: Cold Spring Harbor, 1991, p. 169-213.

11. Ryan, J.J., Schecter, A.J., Masuda, Y. and Kikuchi, M. Comparison of PCDDs and PCDFs in the tissues of Yusho patients with those from the general population in Japan and China. Chemosphere 16:8/9:2017-2025, 1987.

12. Schecter, A.J. and Ryan, J.J. Polychlorinated dibenzo-para-dioxin and dibenzofuran levels in human adipose tissues from workers 32 years after occupational exposure to 2,3,7,8-TCDD. Chemosphere 17:5:915-920, 1988.

13. Schecter, A.J., Ryan, J.J., Päpke, O., Ball, M. and Lis, A. Elevated dioxin levels in the blood of male and female Russian workers with and without chloracne 25 years after phenoxyherbcide exposure: the Ufa "Khimprom" incident. Chemosphere 27:253-258, 1993. 
14. Schecter, A.J. and Ryan, J.J. Persistent brominated and chlorinated dioxin blood levels in a chemist. J Occup Med 34:702-707, 1992.

15. Päpke, O., Ball, M. and Lis, A. PCDD/PCDF in Humans - An Update of Background Data. Organohalogen Compounds, Eco-Informa Press, Bayreuth, Germany 13:81-84, 1993.

16. Fürst, P., Fürst, C. and Wilmers, K. PCDDs and PCDFs in human milk-statistical evaluation of a 6-years survey. Chemosphere 25:1029-1038, 1992.

17. Beck, H., Dross, A. and Mathar, W. PCDD and PCDF esposure and levels in humans in Germany. Environmental Health Perspectives 102 suppl 1:173-185, 1994.

18. Schecter, A.J., Fürst, P., Fürst, C., Groebel, W., Constable, J.D., Kolesnikov, S., Beim, A., Boldonov, A., Trubitsun, E., Vlasov, B., Cau, Hoang Dinh, Dai, Le Cau and Quyng, Hoang Tri Levels of chlorinated dioxins, dibenzofurans, and other chlorinated xenobiotics in food from the Soviet Union and the south of Vietnam. Chemosphere 20:7/9:799-806, 1990.

19. Schecter, A.J., Fürst, P., Fürst, C., Grachev, M., Beim, A. and Koptug, V. Levels of dioxins, dibenzofurans and selected other chlorinated organic compounds in food from Russia. Chemosphere 25:2009-2015, 1992. 